\title{
Different Strokes for Different Folks: Connecting with Students for Academic Success
}

\author{
Michael Gilbert ${ }^{1, *}$ \\ ${ }^{1}$ ATOIRE Communications, LLC, PO Box 845, Flat Rock, NC 28731, USA \\ *Correspondence: ATOIRE Communications, LLC, PO Box 845, Flat Rock, NC 28731, \\ USA. Tel: 1-989-400-7069 E-mail: atoirecomm@gmail.com
}

Received: September 5, 2014 Accepted: September 28, 2014 Published: October 23, 2014

doi:10.5296/ije.v6i4.6269 URL: http://dx.doi.org/10.5296/ije.v6i4.6269

\begin{abstract}
Schools are challenged to provide meaningful learning experiences to prepare students for immediate and long-term success. The controversial Common Core is an attempt to institute a national curriculum in the United States to align with other countries.

Regardless of the approach, academic content is an important starting point for schools. Varying delivery methods are the companions to connecting with students for successful learning experiences. This article addresses how teachers might consider personality aspects in delivering curricula effectively. The methodology of doing so is explained by examining the Process Education Model, its components and implications. Also included are outcomes of several research and application projects.
\end{abstract}

Keywords: Effective communication, Instructional delivery, Perceptions, Motivation, Classroom interaction 


\section{Introduction}

The issues of how to prepare students to compete in a global economy are primary in education today. The "Common Core" is one possible approach for education in the United States. It was the adopted curriculum in 45 states. It is the closest the U. S. has come to a national curriculum, unlike most countries the world, where there is a national educational policy. However, issues regarding how to measure the results have spawned some crucial questions (Altman, 2014). While the "jury is still out" on the Common Core, the focus on delivering a meaningful curriculum remains. A formula to consider for academic success might be:

\section{Content + Process $=$ Academic Success}

Traditional approaches to instructional delivery may no longer be effective.

"OK! Today, you are going to be working by yourselves. If you have any questions, raise your hands, and I will come to you.”

This scenario has been seen in classrooms all over the U. S. It demands that students conform to the way that the teacher wants them to behave. However, not every student is comfortable with static or limited delivery methods or constraining rules. We have learned that students have differing learning styles and ways of processing information (Gregorc, 1982; Kolb; 1984; McCarthy, 1980). Preference of intake modes (auditory, visual, and kinesthetic) (Barbe \& Swassing, 1979) and access to different abilities (analytical, creative, and practical) (Sternberg, et al., 1999) are other considerations for looking at student learning. Also, students may be more adept with some learning styles or focal areas, or "intelligences" (Gardner, 1983).

Classroom structure and limited instructional delivery may be problems in dealing with students who bring home-life baggage to school. They see their "success" as their ability to "shut up and listen to the teacher" (Knaus, 2013, p. 16).

Personality characteristics (Myers \& Briggs, 1943, 1976, 1985; Noland, 1978) may also factor into classroom interactions. Most of these models attempt to depict an individual with regard to one or several aspects of personality and suggest that the individual functions in life and in learning situations with the manifestations of those characterizations.

Kahler (2008), extended his doctoral research on Miniscripts (Kahler, 1973) and described the six personality types of his Process Communication Model (PCM): Harmonizers, Thinkers, Persisters, Imaginers, Rebels, and Promoters. (These are the current descriptors.) None is better or worse, more or less OK, more or less intelligent. He likened personality structure to a six-story condominium, where the first floor represents our foundation, or base - strongest personality type - and where each remaining floor represents the other personality types in order of the strength of each. This generated order of personality types is firmly established about age seven, and the ability to move to the different "floors" of our personality is measurable and predictable. Each personality type has a different set of needs, perceptions, and behaviors that influences how we learn and how we teach. 


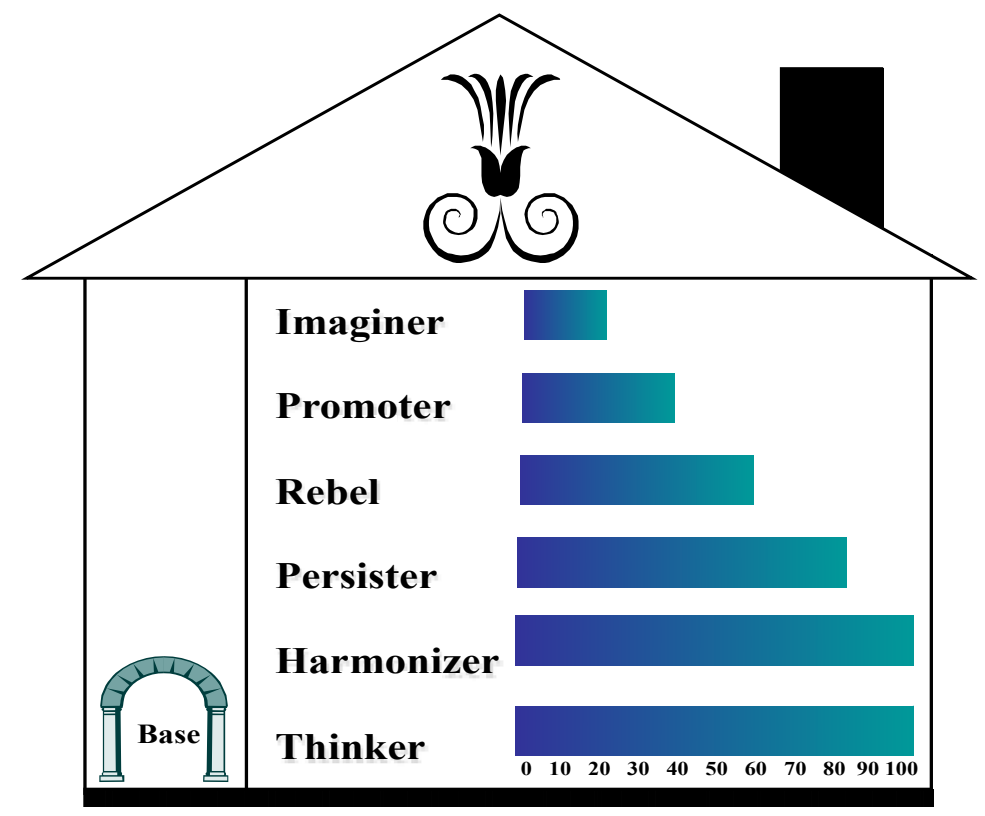

Figure 1. Sample Personality Condominium

Figure 1 (one of 720 possible variations) depicts an individual who sees the world through thoughts. He ( $75 \%$ of people with this structure are male) would focus on ideas and structure. As he would move through his personality structure, he would have some (and varying) energy on each floor to access that personality type.

This multi-dimensional approach is a major asset of PCM. Adapted for education and reconfigured into the Process Education Model (PEM), most students and professional educators limit how they process reality by using only one or two of the six available floors of their personality structure. The diversity of personality types and needs described by the PEM are the focus of this article.

Unique features of the PEM include an inventory validated (Ampaw, Gilbert, \& Donlan, 2013) for purposes of determining an individual's personality structure, what one's psychological motivators are, how one takes in (learns) and gives out (teaches/shares) information, also predicting the negative behaviors a person will manifest when in distress. This aspect of predictability, also the need to measure compatibility, is why PCM was used by NASA in the selection and training of astronauts. Listed below are some "down-to-earth" applications of the PEM.

\section{An Overview of Process Education}

Each personality type has unique characteristics, as follows:

- Harmonizers are warm, compassionate, and sensitive; they like conversation and group-oriented activities. They show their emotions and like to please and 
know they are appreciated. Feelings, instead of logic and thinking, are their forte. (This group comprises $30 \%$ of the North-American population; mainly female $-75 \%$ )

- Thinkers are responsible, logical, and organized. They think before they feel and would rather be recognized than appreciated. (25\%; mainly male $-75 \%)$

- Persisters are observant, conscientious, and dedicated; they prefer being alone or preoccupied with a task. They have strong beliefs about how a job should be done. (10\%; mainly male- $75 \%$ )

- Imaginers are imaginative, reflective, and calm; they usually are passive and are absorbed with their thoughts. They seldom initiate conversations and start withdrawing when there is too much activity around them. (10\%; mainly female $-60 \%$ )

- Rebels are spontaneous, creative, and playful; they react with likes and dislikes and in distress do not answer a question directly. They need fun, attention, and active involvement. They prefer stimulating environments and like active people. $(20 \%$; mainly female $-60 \%)$

- Promoters are resourceful, adaptable, and charming; they modify their behavior to the situation. They need immediate rewards and prefer exciting, stimulating activities. They learn by doing, not by feeling or thinking. (5\%; mainly male $-60 \%$ )

The conclusion that can be drawn from an examination of personality types is that people in education whose needs are not met are going to have difficulties in learning and in meeting performance expectations. For example, a Rebel student is very distractible and needs to have fun. If the learning activity is not "fun," the Rebel may respond, "I just don't get it," as a way of drawing the teacher into playing with him. (In PEM parlance, this is called a "Try Hard" Driver.) A teacher who is not predisposed to spend the extra energy required to meet a Rebel's needs (or who may not have much Rebel energy to draw upon) may suppose that the Rebel is stupid, slow, or immature. This may mean that the Rebel does not perform as expected and fails the activity, the unit, or the course.

In addition, this student may be excluded from the classroom when she appears to act out in a predictable distress (unfulfilled needs) pattern. Of course, excluding the student can only magnify the problem, even though the teacher may breathe a sigh of relief. Continual exclusion can target this student for alternative education, which may only segregate her further. If breaking the classroom rules is the problem, then moving to some alternative settings is problematic. They maintain the "heavy rule sets that make them strikingly similar to the schools from which the students were removed" (Goodman, 2013, p. 50). If the alternative setting does little more than separate compliant from non-compliant students, those who are seen as non-compliant ("difficult") may fare no better academically. They need an environment and delivery methodology to motivate them. 
Another example may be a Harmonizer teacher assigned to a Thinker administrator. The Harmonizer needs sensory things (like pleasing colors, aromas, or familiar pictures) and must experience strong acceptance of herself by others to stay positively motivated. The Thinker, predisposed to efficiency, may perceive sensory things as frivolous and unimportant. The Thinker is also task-oriented and may not have time for the pleasantries and "stroking" needed by the Harmonizer. Should the Thinker consider "praising" someone, that praise is likely to be couched in terms of his motivational need of recognition of work - "Good work! You've increased test scores by 10\%." Since Harmonizers need unconditional recognition as people, the teacher might say to herself, "Why am I just a work unit to him? I want to be liked and appreciated as a person. Colleagues and students aren't just co-workers and pupils to me; they're my extended family."

Not having received the necessary unconditional acceptance needed, the Harmonizer makes mistakes (being driven by a 'Please You" state of mind). The Thinker concludes that praising does not work and begins to judge this person negatively. Ironically, the Harmonizer teacher will connect comfortably with the $30 \%$ of her students who are also Harmonizers, motivating them to learn faster and better.

To paraphrase Johnson (1983): Communication occurs when the listener understands the speaker in the way the speaker wants to be understood. The other side, miscommunication, is that we do not communicate when the listener does not accept the offer to communicate in the manner preferred by the receiver (Kahler, 1988).

Most writers on listening suggest responding is the capstone of most communication interactions - understanding the message and processing it to a response complete the communication event. In responding, the listener becomes the speaker and vice versa. Yet, it is crucial that the response match the needs and perceptions of the individuals for communication to occur.

An example of processing the message and responding appropriately is found in the PEM. The basic components of the PEM are: personality types and sequences, perceptions, channels of communication, psychological needs, driver behaviors, interaction preferences, and failure mechanisms.

Kahler (1992) identified the following perceptions for the six personality types:

- Harmonizers access the world through emotions.

- Thinkers use the lens of thoughts.

- Persisters prefer to view reality through their opinions.

- Imaginers use inactions, preferring to be directed into action by someone or something.

- Rebels connect through reactions (likes and dislikes).

- Promoters prefer actions. 
Even if one does not know what people's personalities are, others' verbal interactions will give meaningful clues into what their perceptions are. [Note: An accurate profile of an individual can be generated by completing the Personality Pattern Inventory (Kahler, 2012). More information is available by contacting the author at atoirecomm@gmail.com.]

Communicating with the personality types is done through identifying specific words, tones, gestures, postures, and facial expressions.

Each personality type has preferences for what works best:

- Imaginers are directable and Promoters like action (the "bottom line"); they prefer to be directed: "Do problems 4-14 on page 26 and check your answers."

- Thinkers and Persisters are work-oriented; they prefer to be asked: "Will you turn in your assignment on Wednesday?" (While the request is not negotiable, Thinkers and Persisters will respond positively to the question.)

- Harmonizers want to feel first; they prefer a personal connection: "I appreciate your nice smile. It's always a pleasure to see you."

- Rebels are driven by likes and dislikes; they communicate first through being upbeat: "Wow! You really did great stuff in knocking out that homework."

We tend to offer our own preferred channel and accompanying view of the world (perception) to others. For example, if I am a Thinker, much of what I say will be couched in terms of ideas and thoughts. If I say, "Do you think that is a good idea?" then I have asked for information and advertised my perceptual bias of the world - thoughts. If I am addressing a Harmonizer, still, I have missed that person's preference. This will be evidenced by a response such as "I feel good about it."

Responses from the other types might be:

"I believe it is a good idea," for Persisters;

"It's okay," for Imaginers;

"I like it," for Rebels; and

“Okay! Go for it!" for Promoters.

If teachers understand the delivery preferences for their students, they can connect with them more effectively and encourage desired behaviors. For example, telling a Harmonizer that the proposed project is not appropriate to meet the assignment requirements might begin with, "I am really glad that you are a member of the group. Your fellow students seem to enjoy working with you." This allows the Harmonizer to receive the message in her strongest perception before hearing, "It might be better to look at another approach." A Thinker teacher who would, by nature, give only the rationale (logic), but the introductory statement of acceptance would reinforce the student. Therefore, communication will occur, and the student would be able to retool without feeling rejected. Attempting to force individuals to accept a communication bias, which is not theirs, will result in misunderstanding and 
miscommunication.

\section{Implications}

Some recent data from one high school district show that many at-risk students are either Promoters or Rebels (Gilbert, 2011). For Harmonizer, Thinker, or Persister educators (the predominant types), communicating with Promoters and Rebels requires more energy than with the other personality types; thus, many students may have unmet needs and experience the distress or severe distress that accompanies this lack of fulfillment. With Thinker as the least-developed personality type of these at-risk students, traditional programs designed to "help" students organize their work better or think more logically are destined to fail; they fare no better than trying to extinguish a fire with gasoline, often with equally inflamed results for both the teacher and student. These students are likely to prime candidates for alternative education or for dropping out of school.

A profound example of the effects of Process Communication came from the Apache Junction (AZ) School District (K-12). Officials of that district chose to upgrade their professional staff in interpersonal skills and classroom control. Every professional staff member attended at least a three-day session on Process Communication. During these three-day sessions, participants learned about PCM, what their personality sequences were, how to energize themselves, and how to arrange to get their psychological needs met daily, weekly, and monthly, how to interact effectively and motivate each student type, how to interpret negative behaviors in students and intervene quickly and effectively, and how to monitor their distress signals and take appropriate, positive action.

District officials reported the following results:

- Employee turnover had been reduced from $43 \%$ to less than 3\% (even with lower salaries than in neighboring districts - reinforcing the argument that salary is not the primary determinant of attracting and retaining staff);

- Employee satisfaction and staff morale reached an all-time high;

- Student achievement at every grade level increased dramatically;

- Failure rates in grades seven and eight decreased from $20 \%$ to less than $2 \%$;

- Disciplinary referrals were reduced to less than $2 \%$ on any given day;

- District dropout rate declined from more than $20 \%$ to less than $9 \%$;

- Graduation rates increased;

- Student entering post-secondary training increased from less than $19 \%$ to more than $43 \%$; and

- Satisfaction of parents and students toward the schooling process improved substantially. (Gilbert, 1992) 


\section{Macrothink}

These results suggest strongly that meeting the communication needs of individuals can play an integral part in school improvement. The outcomes in Apache Junction were so compelling that the district extended the training to include all support personnel, as well as professional staff.

Some equally compelling information surfaced in work done by this author. In looking at a small group of students, some statistically significant data were found - students with higher GPA's (classified by teachers as "easy" to communicate with) can interact with the personality types most like their teachers better than those whose performance is lower (Gilbert, 2011). This supports the notion that grades are partially the ability of students to meet teacher expectations. Conversely, what this means is that those students who are at risk (classified by teachers as "difficult") will probably be at greater risk when confronted by teachers weak in the energy needed to communicate with those student types effectively.

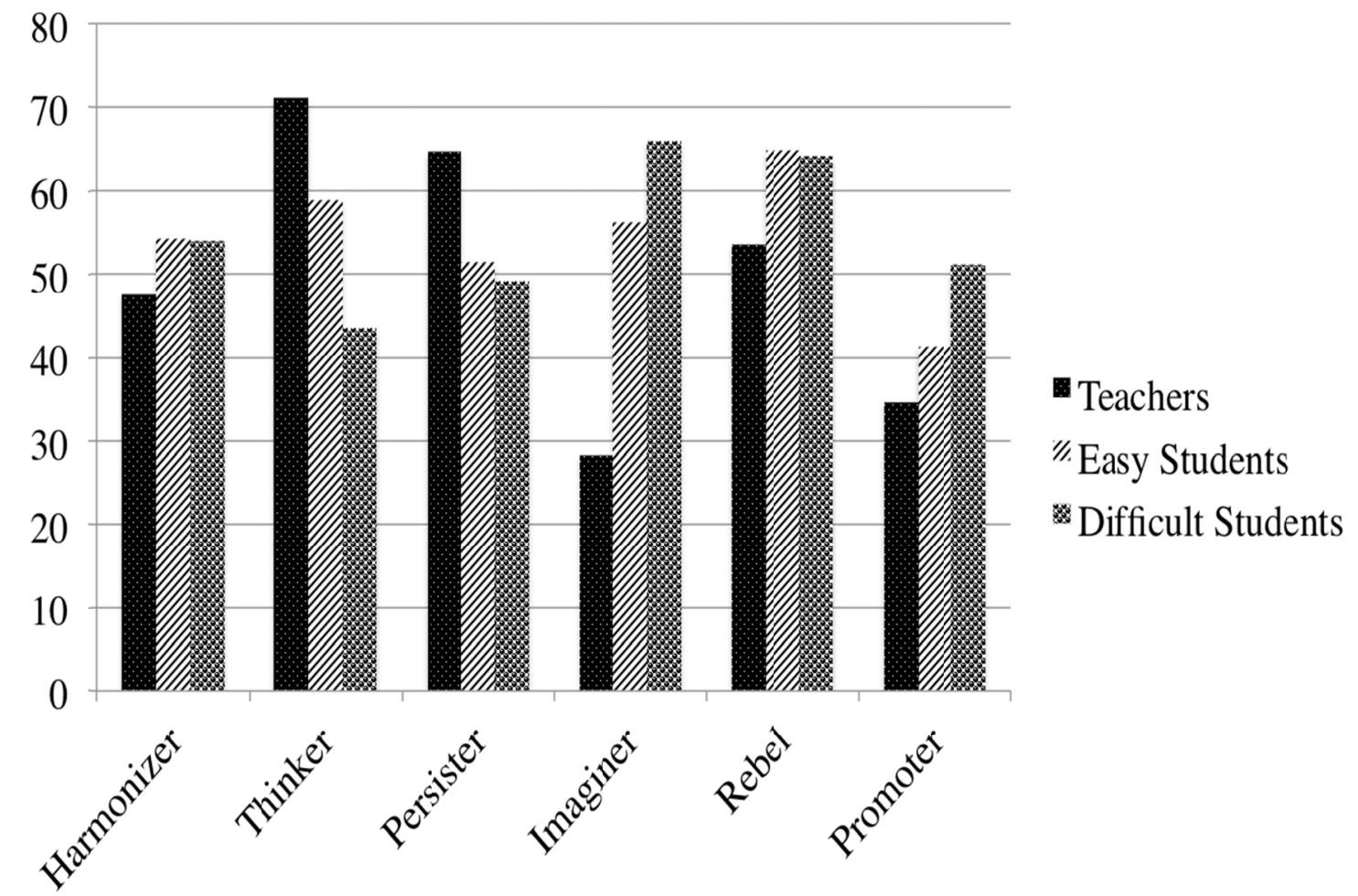

Figure 2. Comparative Personality Strengths

Figure 2 shows the comparative personality strength differences between teachers and students. Note the differences in Thinker and Persister energy and Rebel and Promoter energy between teachers and difficult students. Teachers are significantly stronger in Thinker and Persister attributes, while difficult students have substantially more energy in their Rebel and Promoter parts.

These differences were more evident when student GPAs were compared. The difficult students performed significantly less well than easy students. Of course, the criteria for the 
grades were set by the teachers. Those more closely aligned with their teachers' preferences, the easy students, did better (see Figure 3.) There was almost a full point difference in their classroom achievement as determined by their teachers over a two-year period (Gilbert, 2011).

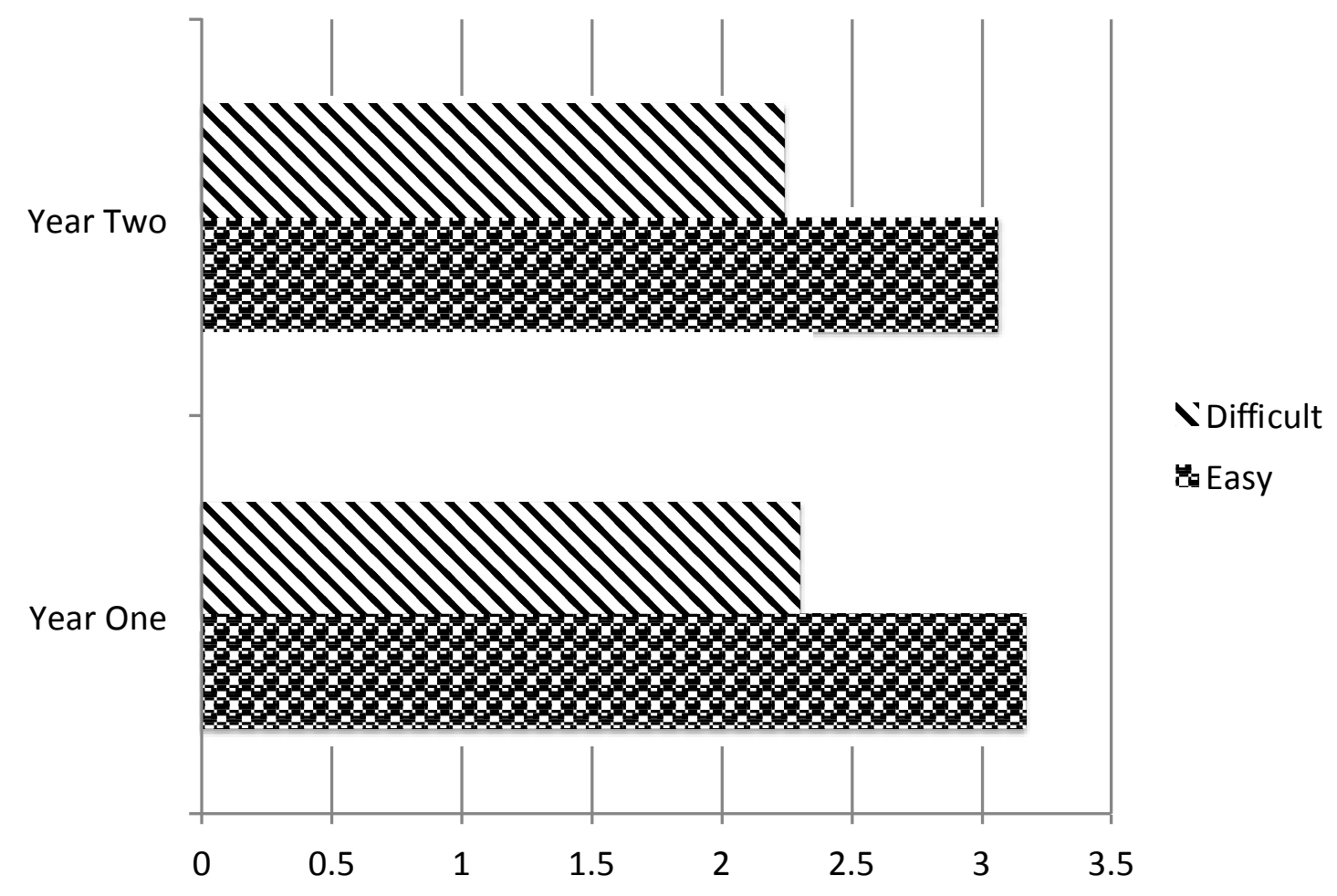

Figure 3. Student Grade-Point Average Comparison

\section{Day-to-day Operations}

An important observation of Process Education in the classroom is that students and teachers are quite capable under positive conditions of using more than one of their personality types. The teacher can offer a lesson appropriate for Harmonizers and have most students succeed. This lesson would most likely be visual and done in small or large groups. (Note that neither the teacher nor the students need to be base Harmonizers for this to happen!). Figure 4 shows the environmental and instructional delivery preferences for the personality types. 


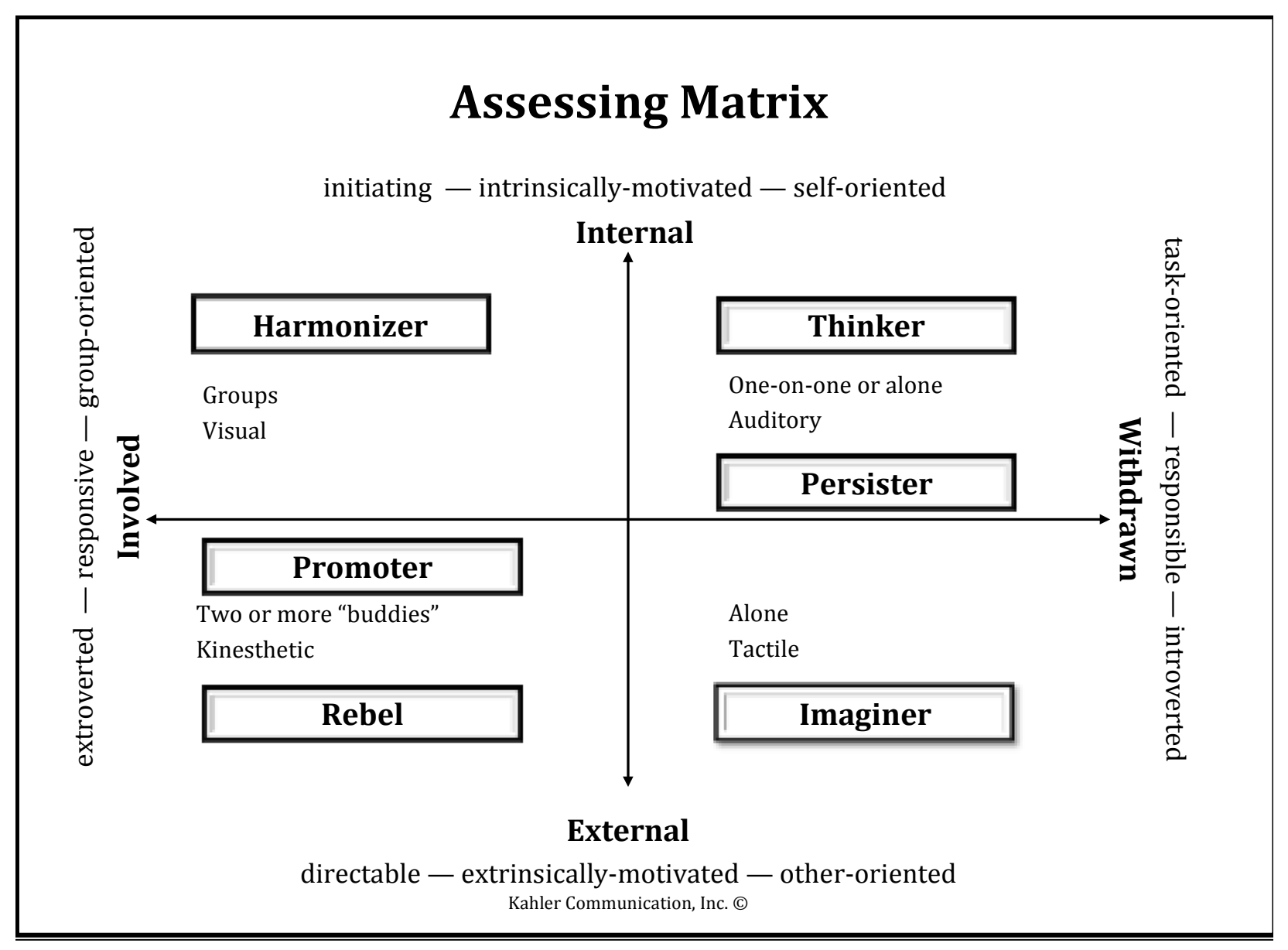

Figure 4. Assessing Matrix

But what if the teacher offers instruction in only one mode? We can predict with certainty which students will lose energy and begin their failure patterns. PEM is very precise; we can anticipate the actual behaviors of a particular type of student before he or she fails. Using this information, the teacher can present early-intervention strategies to invite students back into their success patterns. What makes this work is that students prefer to succeed and will cooperate with a teacher who appears to understand them and accept them and sincerely facilitate their learning.

A somewhat-exaggerated example of an application of PEM is taken from the mathematics curriculum - the workbook (see the opening scenario). At the top of the page is a sample problem and a brief explanation. This is followed by 20 or so similar problems. One page is assigned each day, five days a week, for the six-week unit. Students are to work alone, not talk to their neighbors, and raise their hands for teacher help. If the work is particularly hard, confusing, or boring, we can make some predictions. Thinkers and Persisters will be irritated but work hard to figure out the problems. Rebels will be confused, act out, and perhaps drop their books or fall out of their chairs. Promoters will take some action to have the rules changed for them; they may try to make a deal with the teacher or just not do the work. Harmonizers will feel bad not having personal contact with others and may make "silly" mistakes. Initially, they may smile at their mistakes, but eventually they may cry (especially 
if they are younger students). Imaginers would have the best chance of succeeding, as this would present a set way of doing assignments that does not involve interacting with the teacher or other students. If they cannot do the work, they will wait passively for help.

Staying with the context of mathematics instruction, here is a positive example of how to meet the needs of all of the student types. [Thanks to Roxanne Lee, a PCM-trained teacher in Sheridan, Arkansas.] The activity was to determine rate of speed by applying the component variables of distance and time. The class was divided voluntarily into groups of 2-4 students. Each group had a battery-powered car and a stopwatch. Their task was to name their car, run it over a 15-foot course, and take the average of five runs. Each group's average was then used to predict which car would win a 25 -foot race and what the order of finish will be. Finally, the race was run and the results compared to the predictions.

Thinkers and Persisters were interested in the rules of the activity, the structure of the racecourse, and the data. Rebels liked the group nature of this fun activity, especially the creative naming of the car. Promoters were energized by the incidence (number of activities). Harmonizers enjoyed being with a group and wanted everyone to feel good about what they were doing. Imaginers functioned best as data recorders, being left alone to do their part. All students had an integral part in the lesson and did not experience the distress of not having their needs met.

\section{Conclusion}

Connecting with and motivating students is the most critical aspect of the learning process. The content is typically prescribed, either by governmental requirements, school organization mandates, or textbook publishers. What we have learned is that disconnected students do not learn well and can cause problems in the classroom. Most often, these students have learning preferences different from predominant teaching styles. The Process Education Model offers a unique perspective and suggestions for engaging students effectively and reducing counter-productive classroom behaviors.

Regardless of the model we, as educators, choose, the issue remains the same - connecting with students and staff in meaningful ways is the precursor for effective communication and learning. Changing the processes we use in educational undertakings is more difficult and takes longer than changing our knowledge base. Many educators subscribe to the notion that students and staff must function within specific (singular) personality patterns in order for them to succeed. This is a narrow view that limits people and thwarts their success, in school and beyond; it also ignores to great detriment the diversity of psychological needs we confront as educators. We need to take the time and find sufficient energy to deal effectively with the differences that confront us. Understanding ourselves and others, knowing what negative behaviors mean and what to do about them in the school setting, while focusing more and more on how we communicate, can have profound positive outcomes in education. 


\section{References}

Altman, A. (2014, April 21). Skipping out: Common Core tests spark a parent revolt. Time, p. 12.

Ampaw, F. D., Gilbert, M. B., \& Donlan, R. A. (2013). Verifying the validity and reliability of the Personality Pattern Inventory: Preliminary results. Journal of Process Communication, 1(1), 27-46.

Barbe, W. B., \& Swassing, R. H. (1979). Teaching through modality strengths. Columbus, $\mathrm{OH}$ : Zaner-Bloser.

Gardner, H. (1983). Frames of mind: The theory of multiple intelligences. New York: Basic Books.

Gilbert, M. B. (1992, June). Dreamers, rebels, and others: Personality styles affect communication. Executive Educator, 32-33.

Gilbert, M. B. (2011, July). Connecting with students for academic success: An examination of the Process Education Model. Peer-reviewed paper presented at the $6^{\text {th }}$ Education for a Changing Environment Conference, Manchester, England.

Goodman, G. S. (2013). Student stories: Bear \& Antoine. In Brock, R., \& Goodman, G. S., (Eds.), School sucks: Arguments for alternative education (pp. 44-61). New York, NY: Peter Lang.

Gregorc, A. (1982). Gregorc Style Delineator. Maynard, MA: Gabriel Systems, Inc.

Johnson, D. W. (1983). Reaching out: Interpersonal effectiveness and self-actualization. Englewood Cliffs, NJ: Prentice-Hall.

Kahler, T. (1973). Predicting academic underachievement in ninth and twelfth grade males with the Kahler Transactional Analysis Script Checklist. Dissertation Abstracts International-A, 33(09). (University Microfilms No. AAT 7306052)

Kahler, T. (1982). Process Communication Model: A contemporary model for organizational development. Little Rock, AR: Kahler Communications.

Kahler, T. (1992). The Kahler Process Teaching Model. Little Rock, AR: Kahler Communications, Inc.

Kahler, T. (2008). The mastery of management: Or how to solve the mystery of mismanagement. Little Rock, AR: Kahler Communications, Inc.

Kahler, T. (2012). Personality Pattern Inventory. Hot Springs, AR: Kahler Communications, Inc.

Knaus, C. (2013). Developing urban youth voice. In Brock, R., \& Goodman, G. S. (Eds.), School sucks! Arguments for alternative education (pp. 9-42). New York, NY: Peter Lang. 


\section{Macrothink}

International Journal of Education

ISSN 1948-5476 2014, Vol. 6, No. 4

Kolb, D. A. (1984). Experiential learning: Experience as the source of learning and development. Englewood Cliffs, NJ: Prentice-Hall.

McCarthy, B. (1980). The 4MAT System: Teaching to learning styles with right/left mode techniques. Barrington, IL: Excel, Inc.

Myers, I. B., \& Briggs, K. C. (1943, 1976, 1985). Myers-Briggs Type Indicator. Palo Alto, CA: Consulting Psychologists Press.

Noland, J. R. (1978). Personalysis. Houston, TX: Personalysis.

Sternberg, R. J., Grigorenko, E. L., Ferrari, M., \& Clinkenbeard, P. (1999). A triarchic analysis of aptitude-treatment interaction. European Journal of Psychological Assessment, 15(1), 3-13. http://dx.doi.org/10.1027//1015-5759.15.1.3

\section{Copyright Disclaimer}

Copyright for this article is retained by the author(s), with first publication rights granted to the journal.

This is an open-access article distributed under the terms and conditions of the Creative Commons Attribution license (http://creativecommons.org/licenses/by/3.0/). 